\title{
Multivariate Analysis of Four Strains of Broiler Chickens at Four Weeks of Age
}

\author{
Ibiwoye DI*. and Sola-Ojo FE. \\ Quantitative, Molecular Evolution and Genome diversity Unit, Department of Animal Production, \\ Faculty of Agriculture, University of Ilorin, Nigeria.
}

*Corresponding Author: Ibiwoye D.I, Department of Animal Production, Faculty of Agriculture, University of Ilorin, P.M.B 1515, Ilorin, Kwara State, Nigeria Email: ibiwoyedemilade8@gmail.com.

Article history; Received: February 10th 2021;, Revised. March 29th 2021 ; Accepted May 24th 2021

\begin{abstract}
Eight hundred broiler chickens of four different strains (200 each of Arbor Acre, Hubbard, Marshall and Ross 308) were used to investigate the variations between four strains of broiler chickens commonly reared in North central Nigeria using their body weight and some morphometric body parameters. At four weeks of age, body weight and some morphometric body parameters such as body length, keel length, shank length, body height, drumstick length, thigh length, wing length, shank circumference, comb length, body girth, neck length and beak length were appropriately measured. Data obtained were used for principal component, stepwise discriminant and cluster analyses mainly to identify the traits that could best describe the broiler body conformation. Four (4) principal components were extracted in Arbor Acre broiler strains; this explained 56.68\% of the total variation in the parameters sampled across the strains. Six (6) principal components (PC) were extracted for Hubbard and Ross strains, while three (3) principal components were extracted for Marshall and these explained $59.46 \%$, in Hubbard, $58.67 \%$ in Ross and $55.52 \%$ of the total variance, respectively. The result also showed that PC1 had the largest share of the total variance which was highly significant in the studied morphometric traits and discriminate each of the strain studied. Canonical discriminant functions showed a distinct Hubbard under function1 and a distinct Marshall under function 2. Standardized canonical discriminant analysis indicated that wing length and body girth had highest value for discriminating under function 1 and 2, respectively. This study indicates that available strains of broiler chickens can be distinguished through the use of some multivariate analysis.
\end{abstract}

Key words: Broiler chickens, Growth traits, Principal components Analysis, Strains.

\section{Introduction}

Growth has been described as a complex and highly dynamic physiological process that commences from zygote formation and continues until maturity, while overall growth rate is a function of body weight and morphometric body traits development and could be used as selection criteria for improving body size of chickens and it's very important for breeders to understand and study these traits especially in development of poultry for an improved bodyweight (Adeniji and Ayorinde, 1990, Sola-Ojo and Ayorinde, 2009; Sola-Ojo et al , 2020) . Momoh and Kershima (2008) stated that body weight plays an important role in the determination of several economically important traits and in determining market price in farm animals, while Hanvestein et al. (1994) stated that most chicken growth and fitness traits are controlled by multiple genes, Leeson et al. (1997) established that strains of chicken affects their body weights and weight gain at different ages.

Multivariate analysis has been stated to be an approach that could be useful in analysing performance data of broiler chickens (Sharma, 1996) because it deals with the simultaneous treatment of variables. Some of those multivariate analysis are principal components, factor analysis, cluster analysis, canonical correlation, correspondence analysis, multidimensional scaling analysis, redundancy analysis and canonical discriminant analysis (Johnson and Wichern, 1998) depending on the aim of the study. 
There are different genotypes of broilers in Nigeria market and it is possible to differentiate them using their body weight and morphometric traits through multivariate discriminant analysis (Yakubu et al. 2010; Legaz et al. 2011). Also, it is important to accurately analyse the morphological variables that could assist the breeder in differentiating strains of broilers, at the same time explore the results of these discrimination methods in assessing the potential of each variables studied (Rodero et al., 2011).

This study therefore is aimed at investigating the genetic diversity of four broiler strains that are available in the Nigerian market and commonly reared by farmers using their morphometric parameters. The objective was to examine the relationship among body measurements in some strains of broiler chicken with the view of identifying those components that define body conformation which could be used as a yardstick for improving growth traits in broiler chickens and also aid in identifying broiler chickens strains and aid in discriminating between the strains of available broilers chickens.

\section{Materials and methods}

\section{Experimental Site}

The Experiment was conducted under the ethical approval of the University of Ilorin, Ilorin, Nigeria and was carried out at a Private Farm (Fair and Firm Limited) with all the necessary facilities for rearing broilers chickens. The farm is located at University of Ilorin Road, Tanke Oke-Odo, Ilorin, Kwara State University of Ilorin, Ilorin, Kwara State, Nigeria. Ilorin is in the North Central region of Nigeria located at latitude $9.0820 \mathrm{o} \mathrm{N}$ and longitude $8.6753 \mathrm{o} \mathrm{E}$ of the equator.

\section{Experimental Animal, Housing and Management}

Eight hundred (800) broiler chicks of different strains (Arbor Acre, Hubbard, Marshall and Ross 308) were purchased at a day old from different reputable hatcheries in Ibadan, Oyo State, Nigeria and used for the experiment. The broilers were wing tagged according to strains and weighed on arrival; housed in chicks brooding guard from day old to three weeks, adequate ventilation was provided at the fourth week of the experimental period for the broiler to complete their starter phase. They were grouped into four experimental treatments consisting of two hundred (200) chicks per strain and reared under the same environmental and management conditions and fed the same starter diet formulated to meet their nutrient requirement according to NRC (1994). Feed and water were given ad-libitum throughout the period of the experiment. All the necessary vaccination and medication meant for broiler chicks were administered accordingly (MVM, 2016).

\section{Data Collection}

The recorded behaviour was analysed by four observers and scored using the ethogram in Table1. To ensure At four weeks of age, body weight of individual birds was determined by placing the broiler on the loading pan of the Mettler Toledo® top loading scale and recorded in gram, while thirteen (13) morphometric body measurements \{Body length (BL), Keel length (KL), Shank length (SKL), Body height (BH), Drumstick length (DSL), Thigh length (THL), Wing length (WNL), Shank circumference (SC), Comb length (CBL), Body girth (BG), Neck length (NKL) and Beak length (BKL) \} were done as described by Sola-Ojo and Ayorinde (2011) using a measuring tape $(\mathrm{cm})$ and Vernier calliper (Mitutoyo SS Super Caliper Series 500).

\section{Statistical Analysis}

The data for the body weight and morphometric traits obtained for the individual broiler strains were subjected to principal component analysis using the model:

$$
\mathbf{y}_{1}=\mathbf{a}_{1} \mathbf{x}_{1}+\mathbf{a}_{2} \mathbf{x}_{2}+\ldots \ldots+\mathbf{a n X n}
$$

where $\mathrm{y} 1, \mathrm{y} 2 \ldots . . . \mathrm{yn}$ account for decreasing proportions of the total variance in the original variables x1, x2,......xp. Statistical Package for Social Science SPSS (2013) IBM version 22 was used for the analysis. Principal component analysis (PCA) was done using the procedure of CALCO version 4.5. The factor matrix was rotated using the varimax criterion for easy interpretation of the principal component analysis, and reliability was tested using Kaiser-Meyer-Olkin (KMO) measure of sample adequacy and Barlett's test of Sphericity. Means was separated using least significant difference and tested at $95 \%$ confidence interval. 
Stepwise discriminant analysis of the morphometric traits using the STEPDISC procedure (SPSS, 2013) indicated which variable contributed most to differentiation among the four strains. Canonical discriminant analysis (CANDISC procedure) was performed to obtain canonical variables, canonical coefficients between the four strains based on the selected traits. Broilers were assigned to groups using the canonical functions, and the percentage of correctly assigned birds was an additional measure of differentiation among samples.

\section{Results}

Table 1 reveals the effect of age and strain on linear body measurements. Analysis of variance exposed some growth differences between the broiler strains. Significant $(\mathrm{P}<0.05)$ differences were recorded between the genotypes in all the study traits throughout the duration of the experiment. Ross broiler were heavier, with longer BL, SL and KL, at 4 weeks of age. Arbor Acre had longer DSL and taller in terms of $\mathrm{BH}$ than the other three strains. Hubbard also had superior $(\mathrm{p}<0.05)$ values than Arbor acre, Marshall and Ross strain in SKC, NKL, BKL, THL and WL.

Table 1. Mean and Standard Error of bodyweight $(\mathrm{g})$ and linear body parameters $(\mathrm{cm})$ in the Broiler strains

\begin{tabular}{|c|c|c|c|c|}
\hline TRAITS & Arbor acre & Hubbard & Marshall & Ross 308 \\
\hline $\mathrm{BL}$ & $22.04 \pm 0.09(190) b$ & $22.04 \pm 0.09(190) \mathrm{c}$ & $22.04 \pm 0.09(190) \mathrm{a}$ & $22.04 \pm 0.09(190) \mathrm{d}$ \\
\hline SL & $5.49 \pm 0.02(190) \mathrm{a}$ & $6.09 \pm 0.04(186) b$ & $6.03 \pm 0.03(197) b$ & $6.61 \pm 0.02(194) c$ \\
\hline SKC & $4.21 \pm 0.02(190) a$ & $5.01 \pm 0.03(186) d$ & $4.29 \pm 0.02(197) b$ & $4.74 \pm 0.02(194) c$ \\
\hline NKL & $4.86 \pm 0.03(190) b$ & $7.07 \pm 0.05(186) d$ & $5.32 \pm 0.03(197) c$ & $4.45 \pm 0.02(194) a$ \\
\hline CBL & $2.01 \pm 0.04(190) a$ & $3.39 \pm 0.03(186) c$ & $2.51 \pm 0.02(197) b$ & $2.55 \pm 0.01(194) b$ \\
\hline BKL & $1.50 \pm 0.01(190) \mathrm{a}$ & $2.38 \pm 0.02(186) d$ & $1.69 \pm 0.01(197) b$ & $1.81 \pm 0.01(194) c$ \\
\hline THL & $7.74 \pm 0.04(190) \mathrm{c}$ & $8.03 \pm 0.04(186) d$ & $6.60 \pm 0.04(197) b$ & $6.44 \pm 0.02(194) a$ \\
\hline WL & $10.96 \pm 0.05(190) \mathrm{c}$ & $15.63 \pm 0.06(186) d$ & $10.57 \pm 0.06(197) b$ & $10.03 \pm 0.03(194) \mathrm{a}$ \\
\hline BG & $22.16 \pm 0.09(190) \mathrm{c}$ & $21.77 \pm 0.09(186) b$ & $17.03 \pm 0.08(197) \mathrm{a}$ & $21.60 \pm 0.04(194) b$ \\
\hline DSL & $9.91 \pm 0.04(190) \mathrm{d}$ & $8.78 \pm 0.04(186) c$ & $7.44 \pm 0.05(197) a$ & $8.58 \pm 0.03(194) b$ \\
\hline KL & $7.78 \pm 0.04(190) \mathrm{c}$ & $7.17 \pm 0.08(186) b$ & $5.28 \pm 0.03(197) \mathrm{a}$ & $8.27 \pm 0.04(194) d$ \\
\hline $\mathrm{BH}$ & $19.85 \pm 0.11(190) \mathrm{d}$ & $18.94 \pm 0.06(186) b$ & $16.84 \pm 0.12(197) \mathrm{a}$ & $19.39 \pm 0.07(194) c$ \\
\hline BW & $769.18 \pm 8.48(190) b$ & $758.74 \pm 7.52(186) b$ & $629.54 \pm 8.13(197) \mathrm{a}$ & $936.11 \pm 3.73(194) \mathrm{c}$ \\
\hline
\end{tabular}

Table $2 \mathrm{a}$ to $\mathrm{d}$ shows the eigen values, percentage of the total variance along with the rotated component matrix and communalities of the body measurements of four strains of broiler. The communalities represent an estimate of the variance that is accounted for by the components in each variables studied. It ranged from 0.352 to $0.746,0.406$ to $0.764,0.204$ to 0.736 and 0.415 to 0.722 in Arbor Acre, Hubbard, Marshall and Ross 308 strains, respectively

The eigen values reflected the amount of variance out of the total variance accounted for by each factors. Four principal components were extracted from Arbor Acre broilers with eigen values of 3.543 for the first principal component (PC1), 1.650 for the second principal component (PC2), 1.116 for PC3 and 1.059 for PC4. The four principal components accounted for $56.68 \%$ of the total variance present in the thirteen original variables. PC1 had high loadings (correlations between the components and the variables) on body height (0.774) and thigh length (0.735). PC2 was orthogonal to PC1 and loaded heavily on body girth (0.728) and body length (0.717) Table 2a. The eigen values showed the amount of variance as explained by each factors considered for evaluation of growth traits in the studied broiler chicken strains. Four principal components were extracted from Arbor Acre broilers with eigen values of 3.543 for the first principal component (PC1), 1.650 for the second principal component (PC2), 1.116 for PC3 and 1.059 for PC4. The four principal components accounted for $56.68 \%$ of the total variance present in the thirteen original variables. PC1 had high loadings (correlations between the components and the variables) on body height $(0.774)$ and thigh length (0.735). PC2 was orthogonal to PC1 and loaded heavily on body girth (0.728) and body length (0.717). 
Ibiwoye et al, 2021. Genet. Biodiv. J , 5 (2) ; 53-62

Table 2a. Eigen values, Percentage of total variance along with the rotated component matrix and Communalities of the body measurements in Arbor acre strains of broiler chicken

\begin{tabular}{lccccccc}
\hline Arbor Acre & PC1 & PC2 & PC3 & PC4 & PC5 & PC6 & Communalities \\
\hline BL & -.203 & .717 & .255 & -.210 & - & - & .664 \\
SL & .183 & .177 & .520 & .454 & - & - & .541 \\
SKC & .124 & .578 & -.138 & .137 & - & - & .387 \\
NKL & .262 & .380 & .111 & .355 & - & - & .352 \\
CBL & -.198 & .000 & -.050 & .839 & - & - & .746 \\
BKL & -.055 & -.068 & .828 & -.094 & - & - & .701 \\
THL & .735 & .074 & .022 & .001 & - & - & .546 \\
WL & .586 & .067 & .181 & .082 & - & - & .387 \\
BG & .208 & .728 & -.035 & .067 & - & - & .578 \\
DSL & .590 & .390 & .084 & -.145 & - & - & .528 \\
KL & .442 & .344 & .395 & .179 & - & - & .502 \\
BH & .774 & .035 & -.306 & -.113 & - & - & .707 \\
BW & .430 & .599 & .366 & .224 & - & - & .728 \\
Eigen values & 3.543 & 1.650 & 1.116 & 1.059 & - & - & - \\
\% of the Variance & 27.253 & 12.691 & 8.587 & 8.147 & - & - \\
\hline BL= Body length, SKL $=$ shank length, SC= shank circumference, NKL= Neck length, CBL= comb length, BKL=beak length, \\
THL=thigh length, WNL $=$ wing length, BG=body girth, DSL=drumstick length, KL=keel length, BH=body height, BW=body \\
weight.
\end{tabular}

Table $2 \mathrm{~b}$ showed that six principal components were extracted in Hubbard strains with eigen values of between 1.050 to 1.567 . The six principal components accounted for $59.46 \%$ of the total variance present in the original variables. PC1 had high positive loadings on body length (0.627) while PC2 loaded highly on wing length (0.742) and neck length (0.681). In Hubbard, six principal components were extracted with eigen values of between 1.050 to 1.567 . The six principal components accounted for $59.46 \%$ of the total variance present in the original variables. PC1 had high positive loadings on body length (0.627) while PC2 loaded highly on wing length $(0.742)$ and neck length $(0.681)$.

Table 2b. Eigen values, Percentage of total variance along with the rotated component matrix and Communalities of the body measurements in Hubbard strains of broiler chicken

\begin{tabular}{lccccccc}
\hline Hubbard & PC1 & PC2 & PC3 & PC4 & PC5 & \multicolumn{1}{l}{ PC6 } & Communalities \\
\hline BL & .627 & -.203 & -.092 & .157 & .067 & .106 & .484 \\
SKL & -.028 & .023 & .061 & -.007 & .198 & .848 & .764 \\
SC & .595 & .090 & .096 & -.061 & .365 & -.019 & .509 \\
NKL & .294 & .681 & .065 & .069 & .198 & -.152 & .621 \\
CBL & -.202 & -.169 & .136 & .780 & .075 & .075 & .708 \\
BKL & .104 & .001 & -.108 & .002 & .794 & .160 & .679 \\
THL & .249 & .317 & .494 & .160 & -.325 & .279 & .616 \\
WNL & -.344 & .742 & -.044 & -.065 & -.140 & .131 & .712 \\
BG & -.159 & .173 & .416 & .141 & .403 & -.495 & .656 \\
DSL & -.219 & -.283 & .145 & -.624 & .110 & .195 & 589 \\
KL & .540 & .146 & .017 & -.208 & -.228 & -.062 & .412 \\
BH & .014 & .129 & -.657 & .307 & .083 & .164 & .576 \\
BW & -.016 & .029 & .622 & .118 & .016 & .064 & .406 \\
Eigen values & 1.567 & 1.483 & 1.283 & 1.205 & 1.141 & 1.050 & \\
\% of the & 12.057 & 11.406 & 9.866 & 9.272 & 8.780 & 8.081 & \\
Variance & & & & & &
\end{tabular}

$B L=$ Body length, $S K L=$ shank length, $S C=$ shank circumference, $N K L=$ Neck length, $C B L=$ comb length, BKL=beak length, $T H L=$ thigh length, $W N L=$ wing length, $B G=$ body girth, $D S L=$ drumstick length, $K L=$ keel length, $B H=$ body height, $B W=$ body weight 
Table 2c. Eigen values, Percentage of total variance along with the rotated component matrix and Communalities of the body measurements in Marshall strains of broiler chicken

\begin{tabular}{lccccccc}
\hline Marshall & PC1 & PC2 & PC3 & PC4 & PC5 & PC6 & Communalities \\
\hline BL & .641 & .292 & .011 & - & - & - & .497 \\
SKL & .735 & .139 & .107 & - & - & - & .571 \\
SC & .735 & .030 & .104 & - & - & - & .552 \\
NKL & -.072 & .801 & .145 & - & - & - & .667 \\
CBL & .728 & .183 & .100 & - & - & - & .574 \\
BKL & .067 & .035 & .697 & - & - & - & .492 \\
THL & .283 & .162 & .312 & - & - & - & .204 \\
WNL & .294 & .642 & .018 & - & - & - & .499 \\
BG & .309 & .013 & .539 & - & - & - & .387 \\
DSL & .054 & .047 & .809 & - & - & - & .660 \\
KL & -.069 & .034 & .816 & - & - & - & .671 \\
BH & .213 & .831 & .017 & - & - & - & .736 \\
BW & .482 & .688 & .028 & - & - & - & .706 \\
Eigen values & 3.871 & 2.019 & 1.327 & - & - & - & - \\
$\%$ of the Variance & 29.776 & 15.529 & 10.210 & - & - & - & - \\
\hline BL= Body length, SKL=shank length, SC= shank circumference, NKL= Neck length, CBL= comb length, BKL=beak length, \\
THL=thigh length, WNL= wing length, BG=body girth, DSL=drumstick length, KL=keel length, BH=body height, BW=body \\
weight.
\end{tabular}

In Marshall Strain, three principal components were extracted with eigen values of 3.871 for PC1, 2.019 for PC2 and 1.327 for PC3. The three principal components accounted for 55.52\% of the total variance. PC1 had high loadings on shank circumference (0.735), shank length $(0.735)$, comb length (0.728) and body length (0.641) while PC2 had high loadings on body height $(0.831)$, neck length $(0$. $.801)$, body weight (0.688) and wing length (0.642) Table 2c. In Marshall, three principal components were extracted with eigen values of 3.871 for PC1, 2.019 for PC2 and 1.327 for PC3. The three principal components accounted for $55.52 \%$ of the total variance. PC1 had high loadings on shank circumference (0.735), shank length $(0.735)$, comb length $(0.728)$ and body length $(0.641)$ while PC2 had high loadings on body height (0.831), neck length (0. .801), body weight $(0.688)$ and wing length (0.642).

In Ross strain, six principal components were extracted which accounted for $58.67 \%$ of the total variance in the original variables with eigen values of 1.015 to 1.695 . PC1 was highly correlated with shank circumference (0.702) and shank length (0.692). PC2 had high positive loadings on body length (0.793) and a high negative loading on wing length with a value of -0.653 as shown in Table $2 \mathrm{~d}$.

In Ross 308 broilers, six principal components were extracted which accounted for $58.67 \%$ of the total variance in the original variables with eigen values of 1.015 to 1.695 . PC1 was highly correlated shank circumference (0.702) and shank length (0.692). PC2 had high positive loadings on body length $(0.793)$ and a high negative loading on wing length $(-0.653)$.

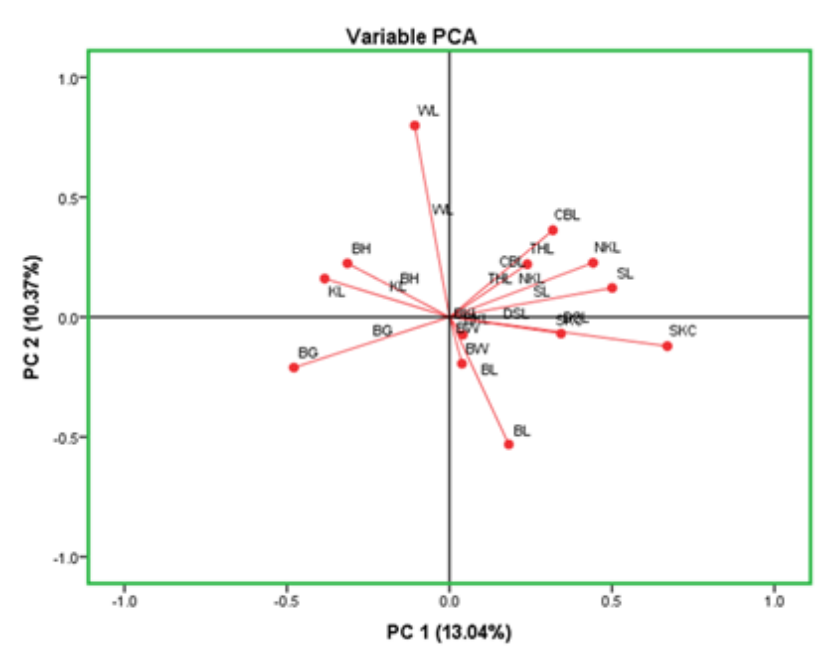

Figure 1. Variable Principal Component Analysis of morphometric parameters of Broiler Strains 
Ibiwoye et al, 2021. Genet. Biodiv. J , 5 (2) ; 53-62

Table 2d. Eigen values, Percentage of total variance along with the rotated component matrix and Communalities of the body measurements in Ross strains of broiler chicken

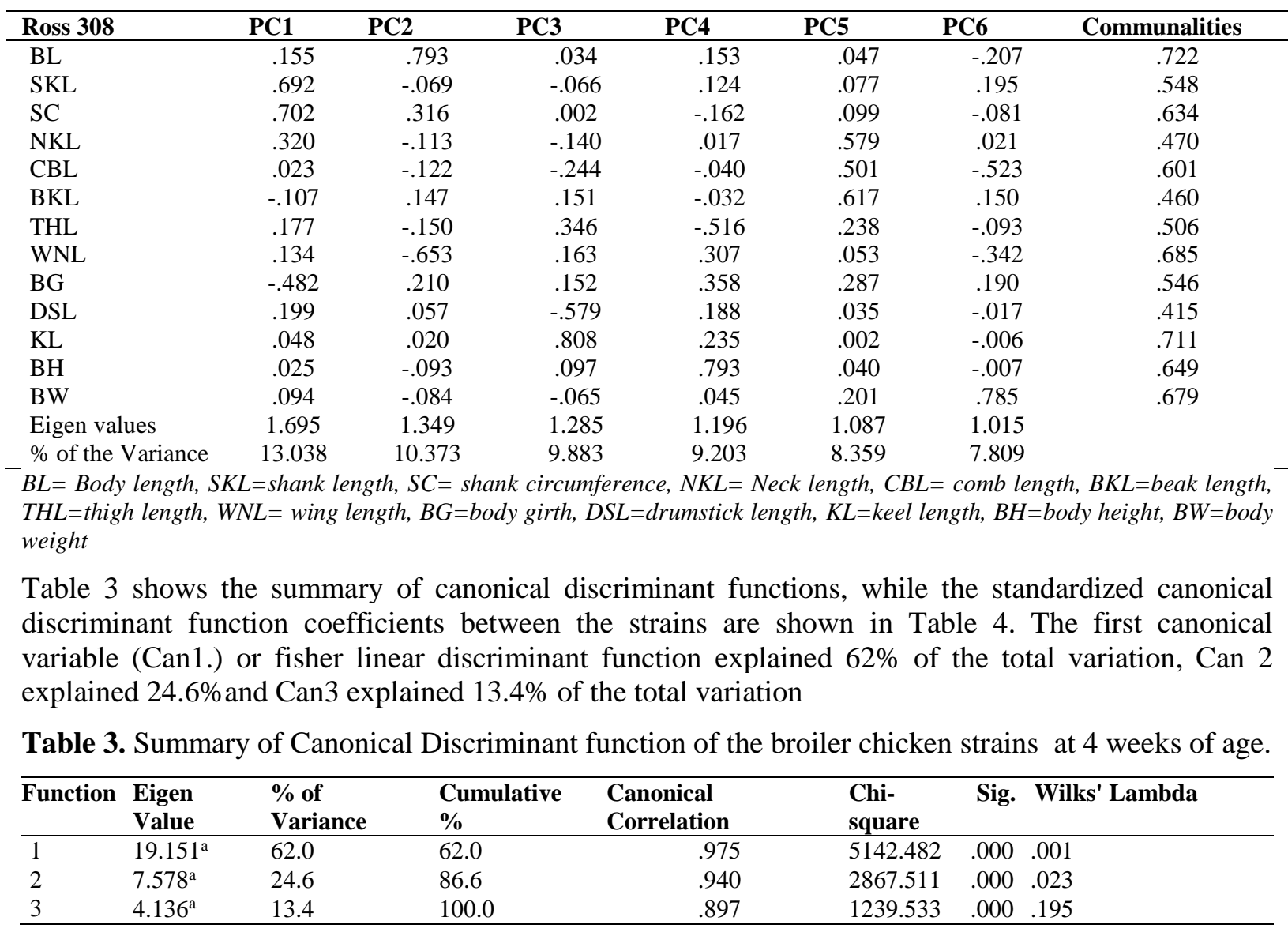

Table 4 revealed that wing length and body girth discriminate across the strains as evident in the standardized canonical functions across the four strains at starter phase of growth with a value of 0.716 and 0.589 .

Table 4. Standardized Canonical Discriminant Function Coefficients of the Broiler Chickens strains at 4weeks of age

\begin{tabular}{cccc} 
& & Function & $\mathbf{3}$ \\
\cline { 2 - 4 } WNL & $\mathbf{1}$ & $\mathbf{2}$ & \\
BG & .716 & .589 & \\
\hline
\end{tabular}

Figure 2 showed that Hubbard birds were marked distinctly from other strains when function1 was considered, while Marshall strains standout discriminately under function 2. The classification results (Table 5) revealed that $99.5 \%$ of Arbor acre were correctly classified, while $100.0 \%$, Hubbard, Marshall and Ross 308 chickens were correctly classified. 


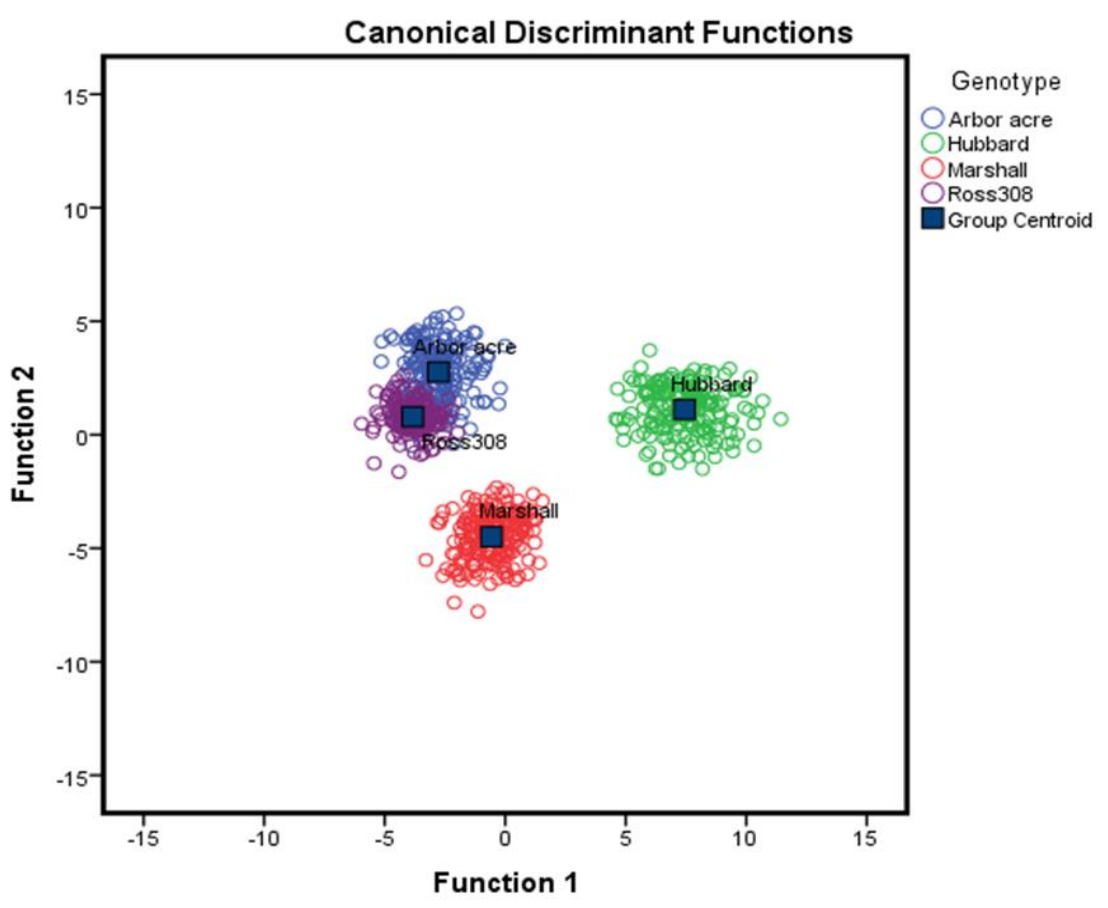

Figure 2. Canonical discriminant function showing the distribution of the four broiler chickens strains at 4 weeks of age. 1, 2, 3, and 4 indicates Arbor Acre, Hubbard, Marshall and Ross 308, respectively

The result output below (Table 5) shows the number of cases correctly and incorrectly assigned to each strain of broilers based on discriminant analysis. The percentage of correctly classified broilers gives a measure of the morphological distinctness between the samples, while the number of misclassified individuals indicates the degree of intermingling between the strains from the analysis performed.

Dendogram using average linkage method showed four major clusters. From the hierachical clustering analysis, It showed that Arbor acre birds were similar $(\mathrm{P}>0.05)$ to Hubbard and Marshall birds but there exist a difference $(\mathrm{P}<0.05)$ between Hubbard and Marshall birds. There is also a similarity $(\mathrm{P}>$ 0.05 ) with ross 308 birds, arbor acre and marshall birds (Figure 3

Table 4. Classification Results for the Discriminant Analysis of the four Broiler Strains at 4 Weeks of Age

\begin{tabular}{|c|c|c|c|c|c|c|c|}
\hline & & \multicolumn{6}{|c|}{ Predicted Group Membership } \\
\hline & & STRAINS & Arbor Acre & Hubbard & Marshall & Ross 308 & Total \\
\hline \multirow[t]{8}{*}{ Original } & Count & Arbor acre & 189 & 0 & 0 & 1 & 190 \\
\hline & & Hubbard & 0 & 186 & 0 & 0 & 186 \\
\hline & & Marshall & 0 & 0 & 197 & 0 & 197 \\
\hline & & Ross 308 & 0 & 0 & 0 & 194 & 194 \\
\hline & $\%$ & Arbor acre & 99.5 & .0 & .0 & .5 & 100.0 \\
\hline & & Hubbard & .0 & 100.0 & .0 & .0 & 100.0 \\
\hline & & Marshall & .0 & .0 & 100.0 & .0 & 100.0 \\
\hline & & Ross 308 & .0 & .0 & .0 & 100.0 & 100.0 \\
\hline \multirow[t]{8}{*}{ Cross-validated } & Count & Arbor acre & 189 & 0 & 0 & 1 & 190 \\
\hline & & Hubbard & 0 & 186 & 0 & 0 & 186 \\
\hline & & Marshall & 0 & 0 & 197 & 0 & 197 \\
\hline & & Ross 308 & 0 & 0 & 0 & 194 & 194 \\
\hline & $\%$ & Arbor acre & 99.5 & .0 & .0 & 99.5 & 100.0 \\
\hline & & Hubbard & .0 & 100.0 & .0 & .0 & 100.0 \\
\hline & & Marshall & .0 & .0 & 100.0 & .0 & 100.0 \\
\hline & & Ross 308 & .0 & .0 & .0 & 100.0 & 100.0 \\
\hline
\end{tabular}




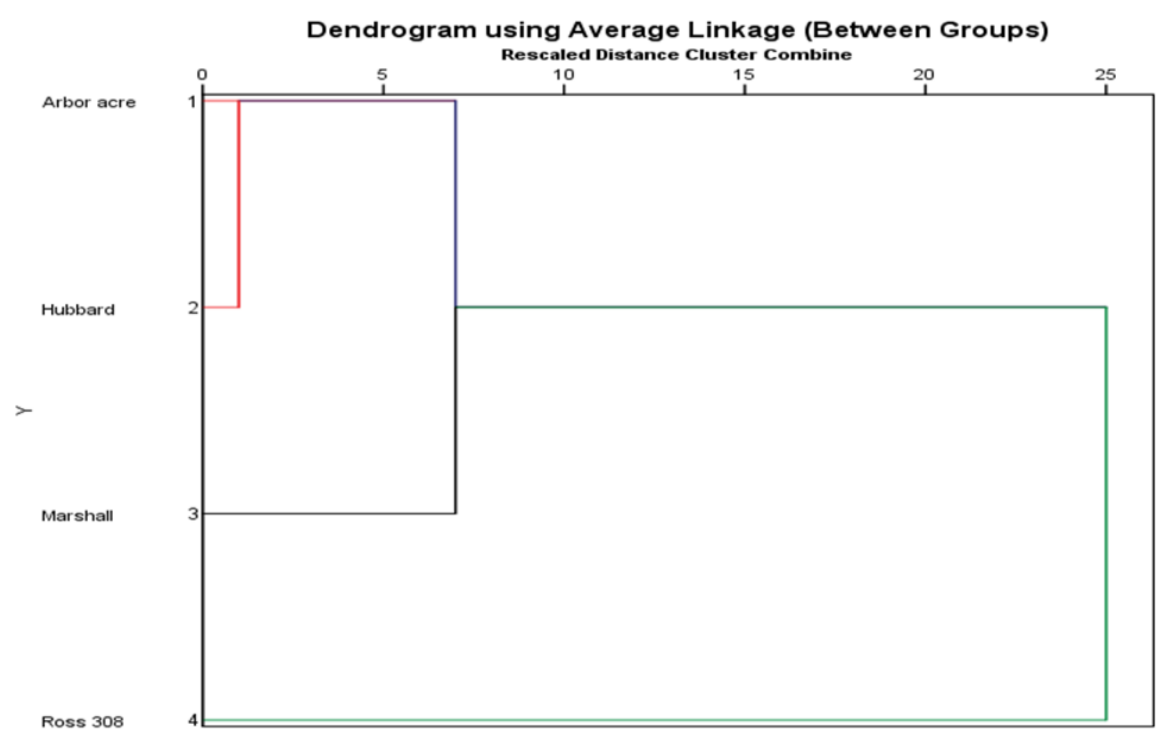

Figure 3. Dendogram from average linkage method(between groups) hierarchical agglomerative clustering among the four broiler genotypes

\section{Discussion}

Results of growth traits showed an increase in all body measurements of each strain as growth advances. It also showed that the body weight of all the strains were significantly different irrespective of age though they were raised under the same condition. Significant difference in the growth performance of different strains of birds was also reported by Giordani et al, (1993). This kind of relationship can be utilized in the genetic improvement of growth through selection which was stated in the works of Omeje and Nwosu (1986). Ross was generally heavier than the other strains. This is in agreement with the report of Akanno et al (2007).

The findings indicated that all the thirteen traits used in this study are useful in the broiler strains classification and the three canonical variables extracted could be used to explain the total variation with wing length and body girth as traits that highly classified the strains, this is in line with the fact that linear body measurements are useful for strains identification and characterization in animals SolaOjo et al. (2020), where significant differences were reported in univariate analysis of four strains of broiler chickens reared under tropical environment. The variations observed in different strains with respect to their body weight and morphometric body parameters could be attributed to genetic diversity in available strains as stated by Sola-Ojo et al. (2020,) and also corroborate the findings of Ikeobi and Peters (1996) where two strains of meat-type chickens were studied.

The eigen values, percentage of the total variance along with the rotated component matrix and communalities of the body measurements in four strains of broiler chicken studied showed the summary of Canonical Discriminant function at 4 weeks of age. The communalities which represent estimates of the variance in each variable accounted for by the components ranged 0.352 to 0.76 across the strains and lower than those reported for Arbor Acre broiler chickens by Yakubu et al. (2010) as well as that of Mendes (2011) where a range of 0.78 to 0.98 were reported and this might be as a results of environmental and management factors peculiar to each locations of study. The discriminant analysis results obtained from this indicated WNL and BG values will be highly useful for discrimination among the four strains studied while the canonical discriminant analysis obtained assisted in weighing the original contribution of each trait to the three canonical variables and this observation was similar to the reports of Rosario et al. ( 2008) and Gutierrez (2011). From this study, it was also discovered that the first canonical variable (Can 1) loaded highly for wing length, while the second canonical variable (Can 2) loaded for body girth; these traits were loaded high enough to show their relevance in discriminating between the four strains of chickens studied at starter phase. The observation could be due to the pattern of growth in the broiler chickens at the starter phase and 
the differences or similarity observed were likely to originate from their genetic background which could be as result of the broilers strains being related by descent as stated by Adekoya et al. (2013). The classification results obtained for the four broiler strains at starter phase showed 99.5 to $100 \%$ predicted group membership across the strain and implies that all data were involved in the classification, this support the assertion of Udeh and Ogbu (2011) where principal component analysis of three strains of broiler chickens were done from their body measurement and found useful in their classification. The hierarchical cluster analysis showed that the morphometric parameters of Arbor acre birds were similar to Hubbard and Marshall birds while the other genotypes were also similar to each other. This observation can be due to their pattern of growth either at the starter phase or finisher phase and this similarity could be from their genetic stand point which means they may be closely related by decent. Dendrogram result revealed that the four genotypes are related to their morphology. This is similar to the earlier report of (Adekoya et al. 2013).

\section{Conclusion}

This study showed that variation exists among the morphometric traits of the four strains of broiler studied and also that body weight and morphometric traits can be used to distinguished available strains of broiler chickens. Principal Component Analysis extracted four (4) components in Arbor Acre strain with PC1 having high loadings on body height, thigh length, drumstick length and wing length in the Starter phase. 6 and 3 Principal Components were extracted in Hubbard, Ross 308 and Marshall Strain, respectively at starter phase and distinct in some traits across the strains.

It also showed that, principal component analysis is useful as a tool in prediction of variations that exist in the available strains of broiler chickens, while wing length and body girth are useful morphometric traits in classification of broiler strains at starter phase. Further research on molecular classification and strains identification is therefore recommended to investigate those morphometric traits that can be used to classify and distinguish the available strains of broiler in Nigeria market.

\section{Acknowledgements}

Special thanks goes to Prof A.A Toye of the Department of Animal Production, University of Ilorin, Nigeria for his incessant advises during and after the research activities. The Management and staff of Fair and Firm Farm International Limited are acknowledged for the permission granted us to house the experimental birds and carry out the data collections in the farm premises.

\section{Funding}

There was no external Funding for this research work.

\section{Availability of data and materials.}

The authors declares that data collected and materials used are available

\section{Authors' contributions}

- Ibiwoye and Sola-Ojo conceived and designed the experiment

- Ibiwoye analyzed and interpreted the data

- Ibiwoye and Sola-Ojo wrote the manuscript, and the two authors revised and approved the final manuscript.

\section{Ethics approval and consent to participate}

This work was carried out under the ethical approval of the University of Ilorin, Ilorin, Kwara State Nigeria and all the authors agreed to participate in the research.

\section{References}

Adekoya KO. Oboh BO. Adefenwa MA. Ogunkanmi LA. 2013. Morphological Characterization of Five Nigerian Indigenous Chicken Types. Journal of Sci. Res. Dev. 2013, Vol. 14: 55 - 66.

Adeniji FO. and Ayorinde KL. 1990. Prediction of body weight from body measurements of chicken Nigerian Journal of Animal Production 17: 42-47. 
Akanno EC. Ole PK. Okoli IC. Ogundu UE. 2007. Performance characteristics and prediction of body weight of broiler strains using linear body measurements. Proceedings 22nd Annual conference of the Nigerian Society for Animal Production, Calaber: 162-164.

Giordani G. Meluzli A. Cristofori C. Calini F. 1993. Study on the performance and adiposity of modern broiler: Comparison among strains. Anim Breed. Abstr., 61: 581-596.

Havenstein GG. Ferket PR. Scheideler SE. Larson BT. 1994. Growth, liveability and feed conversion of 1957 vs 1991 broilers fed broiler diets. Journal of Poultry Science. 73: 1795-1804.

Johnson RA. and Wichern DW. 1998. Applied Multivariate Statistical Analysis, 5th ed., Prentice Hall, Texas.

Leeson S. Caston L. Summers JD. 1997. Layer performance of four strains of leghorn pullets subjected to various rearing programs. Journal of Poultry Science. 76: 1-5.

Legaz E. Cervantes I. Perez-Cabal MA. de la Fuente LF. Martinez R. Goyache F. Gutierrez JP. 2011. Multivariate characterisation of morphological traits in Assaf (Assaf.E) sheep, Small Ruminant Research, 100, 122-130.

MVM 2016. Merck Veterinary Manual 11th Edition.ISBN 9780911910612 Published by Elsevier 12th August 2016. https://www.elsevier.com.

Momoh OM. and Kershima DE. 2008. Linear body measurement as predictors of body weight in Nigerian local chickens. Asset Series A. 8(2), 206-212.

NRC (National Research Council) Nutrient Requirements of Poultry 1994. Washington, D.C: National Academy Press; 1994.

Omeje SS. and CC. Nwosu 1986. Growth and egg production evaluation of F2 and backcross progeny chicks from Nigerian chicken by gold-link crosses. Proc. World Cong. Genet. Applied Livestock Prod., 10: 304-310.

Rodero E. Gonzalez A. Luque M. Herrera M. Gutierrez- Estrada JC. 2011. Classification of Spanish autochthonous bovine breeds: Morphometric study using classical and heuristic techniques, Livestock Science, 143 (2-3).

Rosa'rio MF Silva MAN Coelho AAD Savino VJM Dias CTS. 2008. Canonical discriminant analysis applied to broiler chicken performance. Animal (2008), 2:3 : 419-424 \& The Animal Consortium 2008 doi: 10.1017/S1751731107001012.

Sharma S. 1996. Applied multivariate techniques. John Wiley and sons Inc. New York.

Sola-Ojo FE. and Ayorinde KL. 2009. The Fulani Ecotype chicken: Growth and Feed Utilization Potentials. World Journal of Applied Science and Technology WOJAST. 1 (1): 37-44.

Sola-Ojo FE. and Ayorinde KL. 2011. Repeatability estimates of some growth traits in four broiler strains at different ages. Nigerian Journal of Genetics NJG. 25: 118-123.

Sola-Ojo FE. Ibiwoye DI. Akilapa MA. 2020. Effects of Strain on Body Weight and Morphometric Traits and Their Relationships in Four Broiler Chicken Types During the Starter and Finisher Stages. Journal of Agriculture and Food Environment, 7(1): 9-16. Published by the Faculty of Agriculture, Delta State University, Abraka, Nigeria, and Available online at https://www.jafedelsu.com .

Statistical Package for Social Sciences 2013. SPSS Version 22 IBM Inc. 444 Michigan Avenue, Chicago, IL60611, USA.

Udeh I. and CC. Ogbu. 2011. Principal component analysis of body measurement in three strains of broiler chicken. Science World Journal 6: 11-14.

Yakubu A. Salako AE. Imumorin IG. Ige AO. Akinyemi MO. 2010. Discriminant analysis of morphometric differentiation in the West African Dwarf and Red Sokoto goats, South African Journal of Animal Science, 40, 381-387 